\title{
REMODELING OF PERIAPICAL LESIONS SCAFFOLDING BY BIPHASE CALCIUM PHOS- PHATE CERAMICS - A PILOT STUDY
}

\author{
A. Gusiyska, E. Dyulgerova \\ Department of Operative Dentistry and Endodontics, \\ Faculty of Dental Medicine, Medical University - Sofia, Bulgaria
}

\begin{abstract}
Introduction: Typical chronic apical periodontitis is generally accompanied by periapical bone destruction, which is radiographically observed as periapical radiolucency around the apex. Pathological events in apical periodontitis are mainly characterized by bone destruction and this bone destruction is mediated by osteoclasts which are multinuclear cells derived from macrophages. Although bone tissue possesses the capacity for regeneration, there are many pathological situations in which this capacity is not sufficient to stimulate and realize healing processes. The development of biphasic calcium phosphate ceramic for bone graft is one of the promising biomaterials for better control of the complex processes of bone healing and regeneration.
\end{abstract}

Materials and Methods: The subject of this study were seven clinical cases (seven patients - 4 female and 3 male in ages from $22-53$ years) with radiolucency and radiographical evidence of periapical lesions. The result of this treatment was presented in three groups: I) three of root canals were aseptically instrumented to ISO size 60 (\# 11, 46, 21), II) two of them - to ISO size 70 (\# 11,36), and III) the third group to ISO size 80 (\# 21,22) (Fig.2).

Following the ideology of the injectable implant material [37], this study used as, scaffold fine powder particles of biphase calcium phosphate ceramic mixed with saline solution.

Results: The results of this study are presented in the radiographs listed as Fig. 5, 9, 10 preoperatively and Fig. 6, $7,8,11,12,13$ and 14 postoperatively.

The sequence of replacement of radiolucency with a radioopacity in periapex should be considered as one of the characteristics in remodeling of the processes after treatment.

These findings showed that in a lapse of time the healing processes involve immature bone and fibrous connective tissues.

Discussion: Our positive results are insufficient for suggesting any possible mechanisms expanding healing processes of lesions. But having in mind some data from the literature on bone regeneration, molecular and cellular interaction with calcium phosphate ceramics, it should be mentioned that some results have demonstrated that microporosity and surface activity of ceramic is responsible for bone formation

Concluding remarks: The basic aim of this study is to achieve healing and probably bone regeneration in the clinical treatment of apical lesions, using methods of bone regeneration and tissue engineering.

The positive results of the present pilot study demonstrate: bone remodeling, biomimetic obturation of the translucent apical zone and apical foramen.

Key words: apical periodontitis, bone regeneration, apical obturation

\section{INTRODUCTION}

Apical periodontitis is an inflammatory disorder of periradicular tissues caused by microbial infection within the root canal system of the affected tooth.

Equilibrium is found between microbial factors and host defense that allows the persistence of pathogens in the root canal leading to the formation of various lesions in apical periodontal zone. Apical periodontitis is viewed as the consequence of a dynamic encounter between root canal microbes and host defense [16, 17].

The latter involves cells, intercellular mediators and antibodies. Pathological events in apical periodontitis are mainly characterized by bone destruction and this bone destruction is mediated by osteoclasts which are multinuclear cells derived from macrophages [38]. Apical periodontitis is histologically characterized by the infiltration of various inflammatory cells $[1,18]$.

Typical chronic apical periodontitis is generally accompanied by periapical bone destruction, which is radiographically observed as periapical radiolucency around the apex.

Apical periodontitis is considered to be caused not necessarily by microbial infection alone, but also by other co-factors [13]. It was clear that unlike classical infectious diseases of single specific etiological agents, there are several disease entities that are caused by a consortium of microbial species living in ecological ordered community, known as biofilm and other co-factors such as necrotic pulp and stagnant fluid.

In this context it is important to highlight the fact that 
research in recent decades has documented particularly the microbial factors as leaders in the initiation, development and persistence of apical periodontitis $[4,8,9,10,11,12]$.

The microbial factors and host defense forces engaged together in conflict destroy much of the periodontal apical zone forming various classes of lesions [16]. The initial diagnosis and the difficulties associated with treatment are related to the complex dynamic clinical characteristics of the apical lesions [17]. The ideal accepted endodontically outcome of treatment is to close exactly the root canals system with filling materials and to separate the root canal from the periapex.

The past 20 years of the last century have brought little change, and only modest amounts of the accumulated biological knowledge have found application in the endodontic area[16]. It should be pointed out that in the same time tissue engineering gives rise to a new promising approach in bone regeneration, repair of bone tissue after loss injury or disease following and specially in periodontology[8]. Although bone tissue possesses the capacity for regeneration, there are many pathological situations in which this capacity is not sufficient to stimulate and realize healing processes[3,11]. The mainstay of bone tissue engineering is the scaffolding sytstem mimicking the natural bone in chemical composition to facilitate better osteointegration and subsequent bone tissue formation In this regard calcium phosphate biomaterials are considered as a good choice $[2,14]$.

The development of biphasic calcium phosphate ceramic for bone graft is one of the promising biomaterials for better control of the complex processes of bone healing and regeneration. They are able to be resorbed (degradable through chemical and cellular processes) and they do not induce adverse local tissue reaction [11]. Tissue healing is a complex and dynamic process which enables effective repair of damaged tissue. There is little doubt that appropriate therapy has the capacity to influence the process in a positive way. In this context, allow us to hypothesize that analogical healing phenomena may be displayed in the periodontal apical lesion as consequences of using bone implant biomaterials.

The aim of the present investigation is to follow the healing processes in apical periodontal bone lesions scaffolding with biphasic calcium phosphate ceramics. And also, biomimetic obturation of apical foramen we hope that the nanoparticals of biomaterial placed correctly into periodontal bone lesions and apical foramen could be a good biological scaffold for osteoconduction, bone formation and healing processes in periodontal lesion.

\section{MATERIALS AND METHODS}

The subject of this study were seven clinical cases (seven patients - 4 female and 3 male in ages from 22 - 53 years) with radiolucency and radiographical evidence of periapical lesions. Initial examination found that all the treated teeth were painless without acute exacerbation. Nevertheless, more precise clinical analyses showed that five cases were asymptomatic, and two cases presented tenderness to percussion and palpation. A detailed general medical and dental history was obtained from each patient. Periapical radiographs using parallel technique were taken. The diagnoses were determined by systematic clinical observations and radiographic analyses using periapical index (PAI) with score 3, 4 and 5 by Ostravik. The patient was instructed to brush their teeth regularly and to use chlorhexidine mouthwash after meals. The access cavity was prepared after the application and fixation of the rubber dam (Fig. 1.).

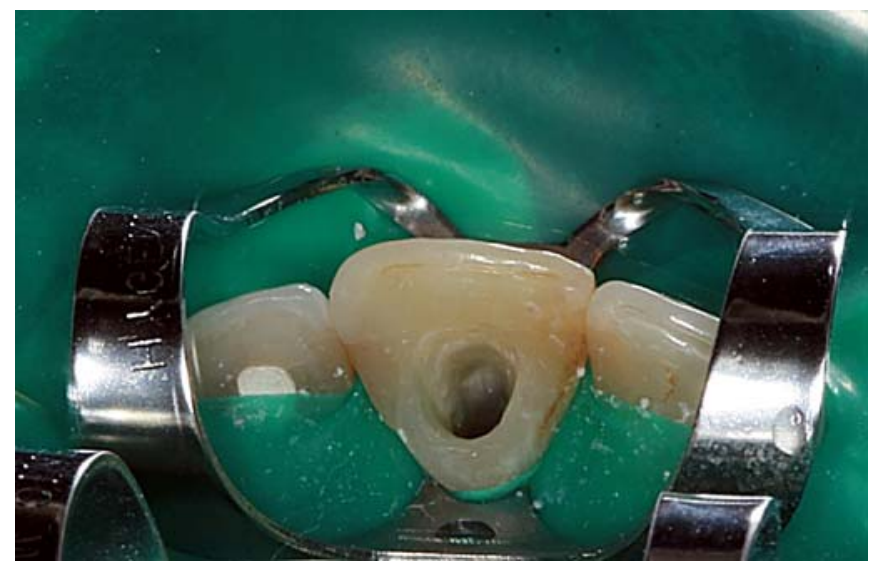

Fig. 1. Access cavity after rubber dam isolation

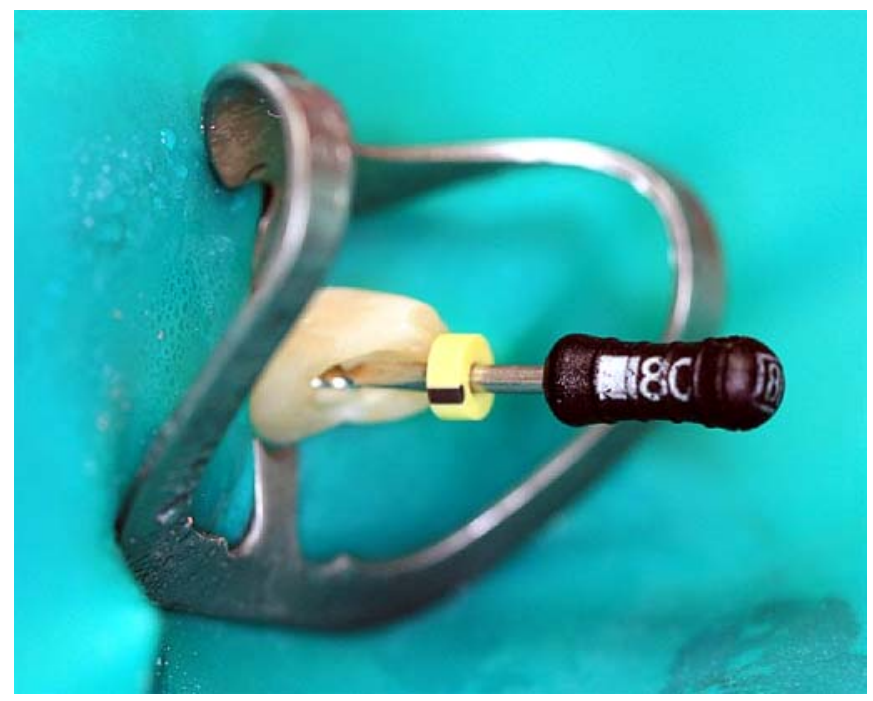

Fig. 2. Master apical file

Microbiological samples were taken twice - in the initial endodontic access and before definitive obturation of the root canals. Working length of root canals was determined after coronal $1 / 3$ preparation, electrometrically with Raypex 5 [VDW, Germany] and compared with radiographic length 
measurements, because of a lack of apical constriction. Mechanical root canal instrumentation was performed with rotary NiTi-instruments under irrigation subsequently with $5.25 \% \mathrm{NaOCl}$ and $17 \%$ EDTA, and $0,9 \%$ saline solution [34, $35,36]$. For 7-10 days was used calcium hydroxide $\left[\mathrm{Ca}(\mathrm{OH})_{2}\right]$ dressing as a medication of choice[19, 23, 33]. At the second appointment $\left[\mathrm{Ca}(\mathrm{OH})_{2}\right]$ was removed with irrigation and the apical control zone was prepared with one more instrument to the working length. The result of this treatment was presented in three groups: I) three of root canals were aseptically instrumented to ISO size 60 (\# 11, 46, 21), II) two of them - to ISO size 70 (\# 11,36), and III) the third group to ISO size 80 (\#21,22) (Fig. 2).

Following the ideology of the injectable implant material [37], this study used as, scaffold fine powder particles of biphase calcium phosphate ceramic mixed with saline solution. The received paste was placed into the defect, using plugger for accurately fit the lesion to the apical foramen $2 \mathrm{~mm}$ above the determined working length. By well compacted and tightly adapted ceramic through the root canal to the apex, was realized biomimetic obturation of the destructed apical foramen. The used operative technique was followed by successful and easy root canal filling and lateral condensation, as is described below.

A standard size gutta-percha cone that matched the master apical file [MAF] was fitted to the working length with tug back Apexit Plus and was mixed according to the manufacturer's instruction. The master cone was coated with sealer -Apexit Plus and gently placed at the working length (Fig. 3).

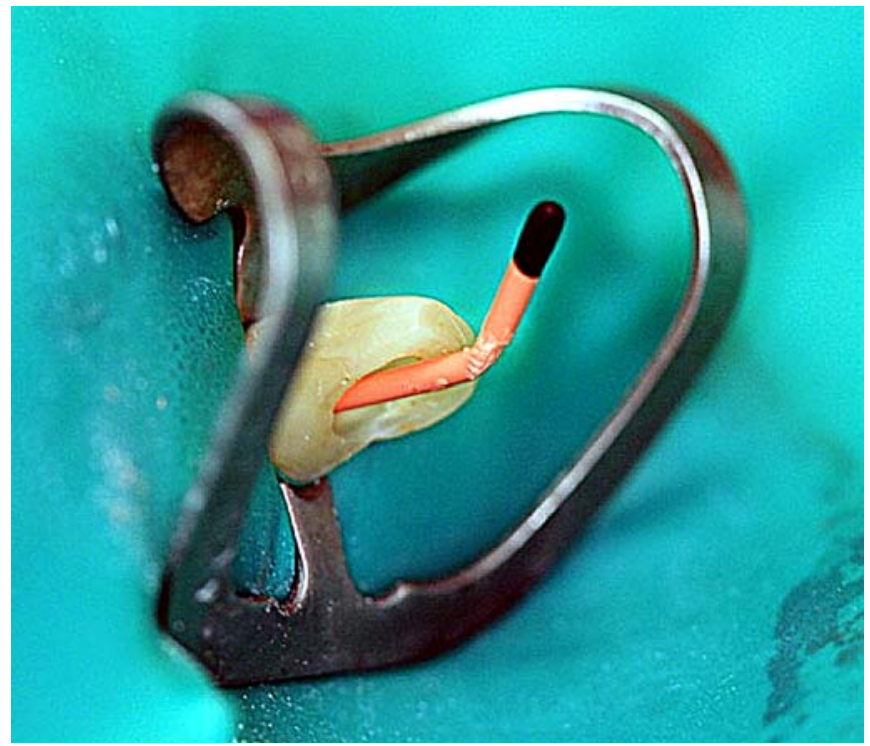

Fig. 3. Master cone selection

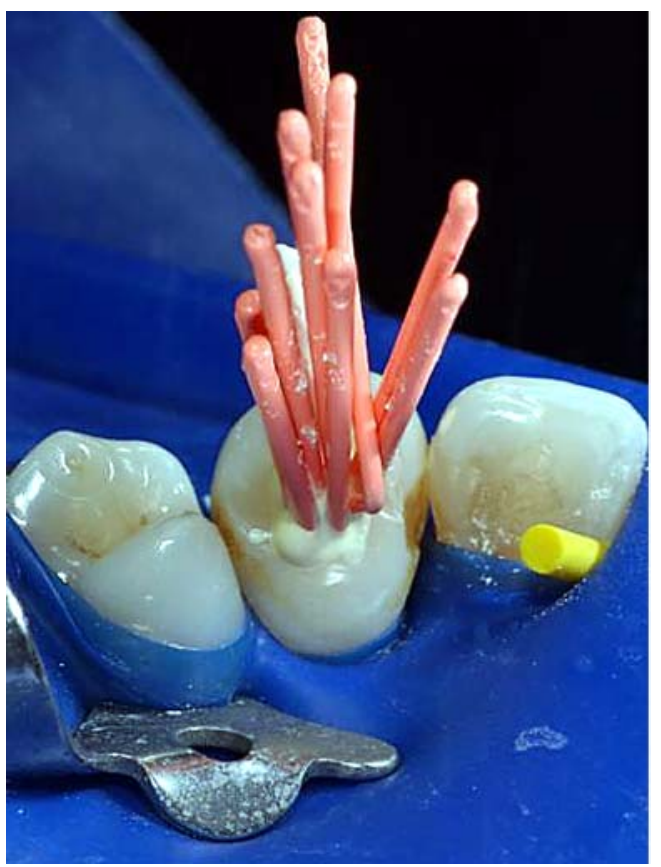

Fig. 4. Lateral condensation

Lateral condensation was then carred out using size gutta-percha cone with endodontic finger spreaders (Maillefer) placed in the first instance to within $1 \mathrm{~mm}$ of the working length. The gutta-percha cones coated with sealer Apexit Plus were laterally condensed until they could not be introduced more than $3 \mathrm{~mm}$ into the root canal (Fig.4).

The biphase calcium phosphate ceramic used in this clinical investigation was tricalcium phosphate and hydroxyapatite $[29,40]$ in particles size about of 1-6 $\mu \mathrm{m}$, and a specific surface $S=29 \mathrm{~m} 2$ measured by BET method. The used material has broad antimicrobial properties [21, 22]. More detailed characteristics of the used bioceramic are beyond the scope of this work, they can be found in other of ours papers $[6,7,24,25,26]$.

\section{RESULT}

The results of this study are presented in the radiographs listed as Fig. 5, 9, 10 preoperatively and Fig. 6, $7,8,11,12,13$, and 14 postoperatively.

The sequence of replacement of radiolucency with a radioopacity in periapex should be considered as one of the characteristics in remodeling of the processes after treatment.

These findings showed that in a lapse of time the healing processes involve immature bone and fibrous connective tissues.

\section{CASE REPORT ONE}

A 45-year old male patient presented a swelling of the soft tissues of tooth 22. Probe depths were within normal limits $-2-3 \mathrm{~mm}$. No mobility was determined and the tooth was non-responsive to a cold test. All other vital teeth in the area 
tested within normal limits to thermal challenge. The patient told us that five years ago he 'underwent a surgical procedure around the tip of the root'. Radiographic preoperative examination (Fig.5) demonstrated severe bone loss around the apical zone and apical resorption. The tooth was with endodontic sealed access but in the root canal, there was no sealer or gutta-percha. Two weeks later, soft tissues in the apical zone looked normal and the tooth was asymptomatic. The tooth was instrumented and sealed according to the methodology and the case was followed-up for four years (Fig. 7 and 8). Postoperative x-ray showed considerable bone apposition and successful apical healing after thorough disinfection and sealing of the root canal (Fig. 6.). It may be assumed that radioopacity is part of a calcification process that may lead to bone formation. The patient returned three years after the placement of the ceramic crown and the tooth was asymptomatic, the soft tissues appeared normal. Radiographic examination revealed complete regeneration of the periradicular tissues (Fig. 8.).

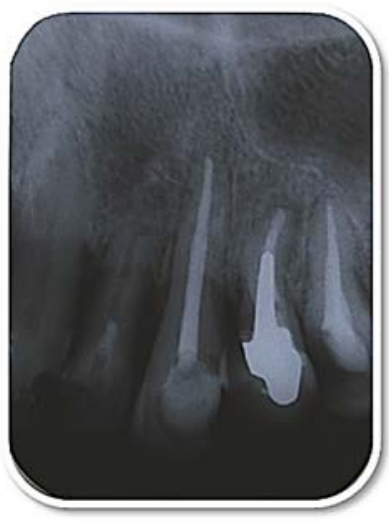

Fig. 5. Preoperative $x$-ray showing periapical lesion and apical resorption

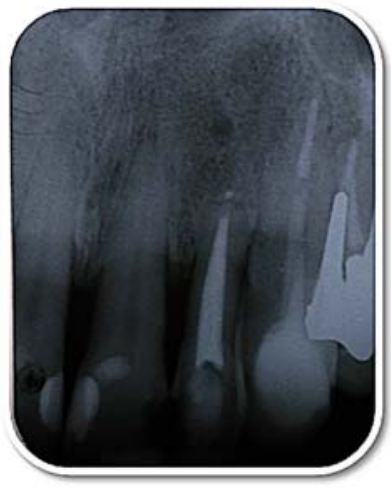

Fig. 7. Postoperative x-ray -1 year later

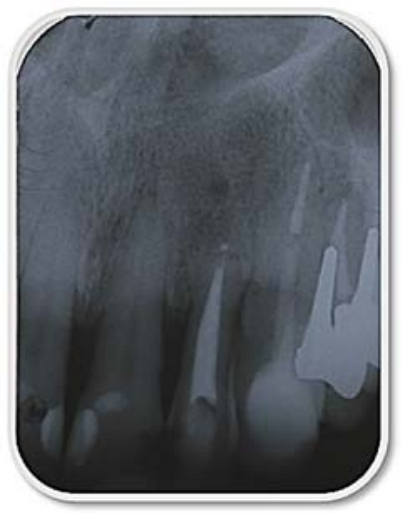

Fig. 6. Postoperative x-ray and bone turnover

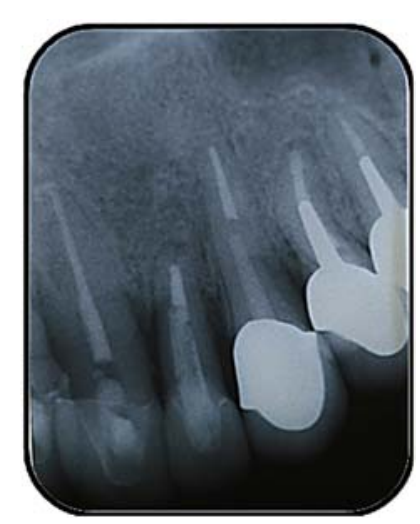

Fig. 8. Postoperative x-ray -4 years later

\section{CASE REPORT TWO}

A 26- year old female patient presented a swelling at the buccal mucosa around tooth 36 (which was restored with amalgam filling before eight years). The rest teeth of the dentition demonstrated a stable periodontal standing. Preoperative radiographic examination revealed severe bone loss around the apical zone on the distal root (Fig. 9, 10). The tooth was instrumented and sealed according the adopted methodology. When the patient returned after 10 days, soft tissues around the treated tooth appeared normal and the tooth was asymptomatic. The root canal dressing - $\mathrm{Ca}(\mathrm{OH})$ 2, was removed with irrigation and apical control zone was prepared with one more instrument to the working length. Then apical zone was obturated with calcium phosphate ceramic and sealed with lateral condensation $(11,12)$. A follow-up examination was done four years after the initial appointment. Radiographic examination revealed regeneration of the periradicular tissues (Fig. 13, 14).

\section{DISCUSSION}

Usually, periodontal lesion depends on the balance between microorganisms, their toxins, and the host defense. It is an inflammation at the tooth apex of a long standing nature and characterized by the presence of a granulomatose tissue predominantly infiltrated with lymphocytes, plasma cells and macrophages. These complex dynamic characteristics of pathogenesis [17] of apical lesion are a real clinical challenge for a multi-step sequence of clinical treatment seeking optimal healing results.

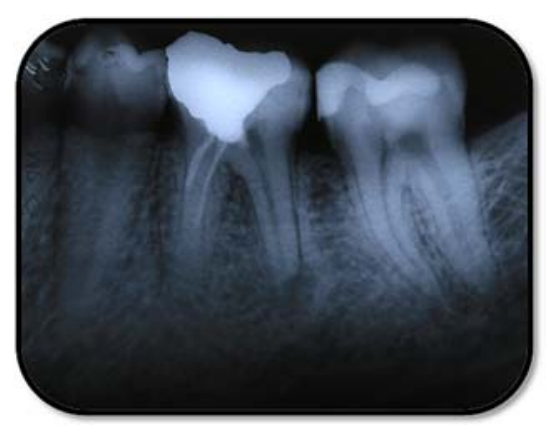

Fig. 9. Preoperative $x$-ray

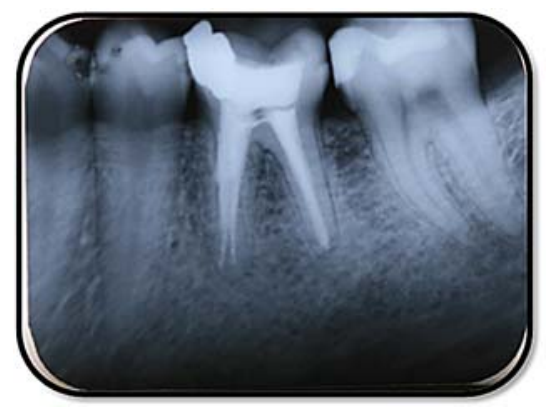

Fig. 11. Postoperative $x$-ray

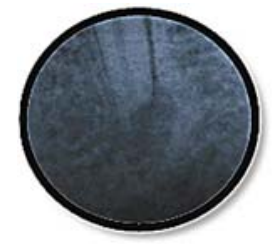

Fig. 10. apical zoom

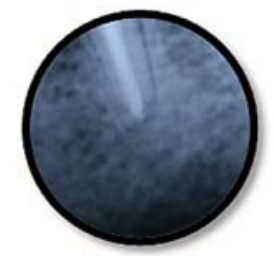

Fig.12. apical zoom 

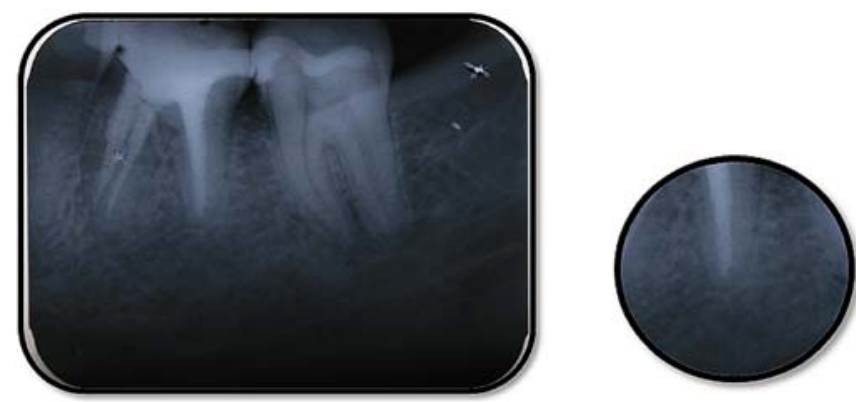

Fig.13. Postoperative x-ray - 4 years later Fig. 14. apical zoom

Our positive results are insufficient for suggesting any possible mechanisms expanding healing processes of lesions. But having in mind some data from the literature on bone regeneration, molecular and cellular interaction with calcium phosphate ceramics, it should be mentioned that some results have demonstrated that microporosity and surface activity of ceramic is responsible for bone formation [9]. In addition, through a dissolution-precipitation process, the development of bone-like mineral layer may initiate bone formation either by mimic bone mineral structure or by the presence of osteogenic compounds [27].

In this context, it is appealing to select or combine calcium phosphate phases that can tailor the bone resorption kinetics and also their stimulating effect on the bone formation. Although $\mathrm{Ca}^{+2}$ from $\mathrm{Ca}(\mathrm{OH})_{2}$ may seem to play a role by activating $\mathrm{Ca}^{+2}$ - dependant adenosine triphosphatase in the repair potential $[5,32]$. All these phenomena are associated with reactivity to bone binding and the formation of an interfacial mineralized layer between bioceramic and bone tissue [11]. Seltzer, Soltanoff and Bender [31] observed in a series of studies that periapical lesions have the potential for healing without surgical intervention. Studies of the healing processes in apical periodontal lesion using nonsurgical scaffold implantation have not been done and its healing mechanisms are profoundly unknown. The suggestion to apply bone tissue engineering in the field of endodontic treatment of apical periodontitis provokes clinical interest but gives rise to a lot of sophisticated questions which require more detailed study. [39]. Interaction between bioceramic implant material and its surrounding tissue is highly complex, a probably due to non-equilibrium conditions and to the undefined amount of compounds playing role in these interaction processes.

To our best knowledge, there are no reports in the literature about the non-surgical treatment of apical lesions scaffolding with calcium phosphate biomaterials.
The tissue dynamics of periodontal healing after root canal treatment are generally not well known. However, certain deductions can be made from the data available on normal healing and bone regeneration of marginal periodontitis using bioceramic implant materials [3].

The patterns of healing depend on several factors two of which are decisive for the regenerative potential and the speed with which the tissue cells bordering the defect [20].

A periodontal scar probably develops because precursors of soft connective tissue colonize both the root and the periapical zone and may occur before the appropriate cells, which have the potential to restore various structure components of the apical periodontium are able to do so[16].

The positive results of this pilot study allow us to point out that scaffold and biomimetic apical obturation with calcium phosphate have potential healing effects on the apical lesions, in chronic apical periodontitis. Nevertheless, there are a lot of complicated, pending questions with enormous theoretical, biological and practical impact.

Generally, dental materials used in endodontic practice are foreign materials with little connection to normal biological processes. It is time to move beyond our traditional understanding and begin to lod for new topics with bio implant-materials and regenerative concepts of treatment.

New ideas are emerging that should be expanded and exploited [28, 30]. In the light of these arguments, it should be pointed out that calcium phosphates are osteoconductive and allow formation of bone on their surface, serving as scaffold. Processes of cell interaction on scaffolds are highly dynamic and depend on various parameters influencing cells activity, and they are not yet fully understood.

\section{CONCLUDING REMARKS}

Advancement of scientific knowledge on the genesis, pathologic nature and clinical behavior of periapical lesion and its successful treatment in various clinical trials are beginning to favor non-surgical approaches.

The basic aim of this study is to achieve healing and probably bone regeneration in the clinical treatment of apical lesions, using methods of bone regeneration and tissue engineering.

The positive results of the present pilot study demonstrate: bone remodeling, biomimetic obturation of the translucent apical zone and apical foramen.

These findings are promising for the use of calcium phosphate biomaterials in endodontic treatment of apical periodontal lesion.

\section{Acknowledgements}

This work is financially supported in part by Bulgarian Ministry of Education and Science under Project X1509. 


\section{REFERENCES}

1. Akamine A., H. Anan, T. Hamachi, K. Maeda; A histochemical study of behavior of macrophages during experimental apical periodontitis in rats. $J$ Endod 1994; 20:474-8.

2. Barrere, F., C.A.van Bitterswijk, K. de Groot.: Bone regeneration: molecular and cellular interaction with calcium phosphate ceramics. Int. J. Nanomedicine 2006:1,317332 .

3. Bartold, M, C. A.G.Mc Culloch, A.S. Narayann, S Pitaru: Tissue engineering: a new paradigm for periodontal regeneration based on molecular and cell biology. Periodontology 2000 2000; 24:253-269.

4. Cacchioli A., B. Spaggiari, F. Ravanetti. F. Martini, P. Borgatti, C. Gabbi: The critical sized bone defect: morphological study of bone healing. Ann.Fac.Medic Vet . di Parma 2006; Vol. XXVI: 97-110.

5. 3alt S, Serper A, Цzzelik B, Dalat D. $\mathrm{pH}$ changes and calcium ion diffusion from calcium hydroxide dressing materials through root dentin. $J$ Endod 1999; 25:329-31.

6. Dyulgerova E. - Calcium phosphates and mineralized oral structures (demineralization, remineralization and reconstruction). $D$ Sci Thesis, Sofia (1993).

7. Dyulgerova E, Kirov GN, Atanassova E. Calcium phosphate ceramic material for reconstruction of bone with periodontal defects and method for its preparation. Bulgarian patent No.42199 (1987) (in Bulgarian).

8. Ellingen E.J., Thomsen P., Lyngstadaas P. Advences in dental implant materials and tissue regeneration. Peridontology 2000, 2006; 41:136-156.

9. Habibovic P., Woodsfield T., K. de Groot, C. van Blitterswijk. Predictive value of in vitro assays in bone and cartilage repair - What do they really tell us about clinical performance? 2005, Special issue in: Tissue Eng. J. P. Ficher

10. Jiang HW, Zhang W, Ren BP, Zeng JF, Ling JQ. Expression of toll like receptor 4 in normal human odontoblasts and dental pulp tissue. J Endod 2006;32:747-751.

11. Le Geros RZ. Properties of osteoconductive biomaterials: calcium phosphates. Clin Orthop Relat Res 2002; 395:81-98.

12. Martinho FC, Gomes BP. Quantification of endotoxins and cultivable bacteria in root canal infection before and after chemomechanical preparation with $2.5 \%$ sodium hypochlorite. J Endod 2008;34(3):268-272.

13. Matsushita K, Tajima T, Tomita K, Takada H, Nagaoka S, Torii M. Inflammatory cytokine production and specific antibody responses to lipopolysaccharide from endodontopathic black-pigmented bacteria in patients with multilesional periapical periodontitis. J Endod 1999;25:795-9.

14. Murugan, R., S. Ramakrishna: Development of cell-responsive nanophase hydroxyapatite for tissue engineering $\mathrm{Am} \mathrm{J}$ Biochem Biotech 2007;3(3):118-124.

15. Mutoh N,Tani-Ishii N, Tsukinoki N, Chieda K, Watanabe K. Expression of Tolllike receptor 2 and 4 in dental pulp. $J$ Endod 2007; 33(10):1183-6.

16. Nair, P.N.R. Apical periodontitis: a dynamic encounter between root canal infection and host response .Periodontology 2000,1997;13(1):121-148.

17. Nair P.N.R. Pathogenesis of apical periodontittis and the causes of endodontic failures.Crit Rev Oral Biol Med 2004; 15(6):348-381

18. Nair P.N.R.: On the causes of persistent apical periodontitis: a review. Int Endod J 2006; 39(4):249-281.

19. Nelson-Filho P, Leonardo MR, Silva LAB, Assed S.Radiogrphic evaluation of the effect of endotoxin (LPS) plus calcium hydroxide on apical and periapical tissues of dogs. J Endod 2002; 694-9.

20. Nelson, M., G. Balasundaram, T. J. Webster: Increased osteoblast adhesion on nanoparticulate crystalline hydroxyapatite functionalized with KRSR. Int $J$ Nanomedicine 2006; 1(3):339-349.

21. Opalchenova G, Dyulgerova E, Petrov OE. A study of influence of biphase calcium phosphate ceramics on bacterial strains. In vivo approach.J. Biomed. Mater. Res.1996;31(2):219-226.

22. Opalchenova G, Dyulgerova E, Petrov OE. Effect of calcium phosphate ceramics on gram-negative bacteria resistant to antibiotics. J. Biomed. Mater. Res.1996; 32(3):473-9.

23. Ozdemir H.O., Ozcelik B., Karabucak B., Cehreli Z.C., Calcium ion diffusion from mineral trioxide aggregate through simulated root resorption defects. Dent Traumatol. 2008 Feb; 24(1):70-3.

24. Petrov O.E, Dyulgerova E, Popova R, Opalchenova G. Quantitative power XRD study of sintered biphase Ca-P biocaramics during sterilization. Mater. Letters 1992; 14:103-106.

25. Petrov O.E, Dyulgerova E, Pertov L, Popova R. Characterization of calcium phosphate phases obtained during the preparation of sintered biphase Ca-p ceramics. Mater. Letters 2001;48(3-4):162-167.

26. Pitts DL, Williams BL, Morton TH.Investigation of the role of endotoxin in periapical inflammation. J Endod 1982;
$8: 10-8$.

27. Ripamoti, U.: Osteoconduction in porous hydroxyapatite implanted in heterotopic sites of different animal models. Biomaterial 1996; 17(1):31-35.

28. Ratner, B.D. New ideas in biomaterials science - a path to engineered biomaterials. J Biomed Mater Res 1993; 27(7):83750.

29. Ratner, B, D The engineering of biomaterials exhibiting recognition and specificity $J$ Mol Rec 1996; 9: 617-25.

30. Ratner, BD. Replacing and renewing: synthetic materials, biomimetics and tissue engineering in implant dentistry. $J$ Dent Educ 2001; 65: 1340-1347.

31. Seltzer, Soltanoff, Bender. Epithelial proliferation of periapical lesions. Oral Surg 1969; 27:111-5.

32. Seux D, Couble ML, Hartmann DJ, Gauthier JP, Magloire H. Odontoblast-like cytodifferentiation of human dental pulp 'in vitro' in the presence of a calcium hydroxide -containing cement. Arch Oral Biol 1991; 36:117-28.

33. Silva LAB, Nelson-Filho P, Leonardo MR, Rossi MA, Pansani CA. Effect of calcium hydroxide on bacterial endotoxin in vivo. J Endod 2002; 28(2):94-8.

34. Siqueira JF Jr et al.Bacteriologic investigation of the effects of sodium hypochlorite and chlorhexidin during the endodontic treatment of teeth with apical periodontitis. Oral Surg Oral Med Oral Pathol Oral Radiol Endod 2007; 104(1): 122-30.

35. Trope M., Debelian G. Endodontic treatment of apical periodontitis; in Essential Endodontology eds Orstavik D, Pitt T. Blackwell Mungsgaard Ltd 2008, 347-380.

36. Vianna ME, Horz HP, Gomes BP, Conrads G. In vivo evaluation of microbial reduction after chemo-mechanical preparation of human root canals containing necrotic pulp tissue. Int Endod J 2006; 39(6):484-92.

37. Daculsi G.Micro Macroporous Calcium Phosphate Bioceramics.Business Briefing: Global Surgery 2004; 1-4.

38. Udagawa N. The mechanism of osteoclast differentiation from macrophages: possible role of T- lymphocytes in osteoclastogenesis Journal of bone and mineral metabolism 2003, 21 (6):260-64.

39. Wang M. Composite scaffolds for bone tissue engineering. Am J Biochem Biotech 2006; 2(2):80-84.

40. Webster T. J., Ergun C., Doremus R. H., Siegel R.W., Bizios R.Enhanced functions of osteoblasts on nanophase ceramics. Biomaterials 2000; 21(17):1803-1810. 